\title{
A Morphological Study of Tongue and its Role in Forensics Odontology
}

\author{
Abraham Johnson*1, Binita Gandhi ${ }^{2}$ and Sandra Ernest Joseph ${ }^{3}$ \\ ${ }^{1}$ Institute of Forensic Science, Gujarat Forensic Sciences University, India \\ ${ }^{2}$ Department of Oral and Maxillofacial Pathology, College of Dental Science and Research Centre, India \\ ${ }^{3}$ Research Associate, Lambda Therapeutic Research Limited, India
}

Submission: February 03, 2018; Published: February 19, 2018

*Corresponding author: Abraham Johnson, Assistant Professor, Institute of Forensic Science, Gujarat Forensic Sciences University, India, Email id: drabrahamjohnson4000@yahoo.com

\begin{abstract}
Forensic odontology is a branch of dentistry that mainly deals with the identification based on individual's oral structures. The tongue is a unique structure that presents both geometric shape as well as physiological texture information that may be potentially useful in identity verification. The present research was taken over the people to study and analyse the morphological shape and texture of the tongue and demonstrate their importance as an aid in human identification. For the study, clinical examination, photographs and impressions were taken of the tongue. The undertaken study showed a qualitative result among different sex and age groups. It can be opined that the human tongue promises to deliver a level of uniqueness in shape, texture and is suitable for the use in identity recognition.
\end{abstract}

Keywords : Tongue print; Biometric, Identification; Forensic odontology; Forensics

\section{Introduction}

Human identification is one of the challenging areas that man has been confronted with. The forensic odontologist mainly deals with the identification based on recognition of unique features present in an individual's oral structures. The tongue is very unique vital organ and its vitality is well inscribed in Traditional Chinese Medicine as "Tongue of life". It is known to be a mirror of the oral and general health. The human tongue is encased within the oral cavity and can be easily drawn out and displayed for inspection and palpation purposes [1]. It promises to deliver uniqueness and has many properties that make it suitable for identity recognition.

Every individual has unique tongue in terms of shape and surface textures. It is the only internal organ that can be stuck out of mouth for inspection, and yet it is otherwise well protected in the mouth and is difficult to forge [2]. It presents both geometric shape information and physiological texture information which are potentially useful in identity verification applications [3]. The shape of the individual tongue is constant, not withstanding its instinctive squirm and its physiological textures are invariant even as the coating of the tongue changes. Analysing the lingual morphological aspects by the alginate moulding technique, is the most reliable technique for duplicating even the minute details, with the help of which a forensic dentist can predict a person's identity. The purpose of the study is to analyse the morphological shape and the texture of the tongue. The rationale of introducing tongue prints in forensic is because of their importance as an aid in human identification.

\section{Materials and Methods}

In the present study, basically a qualitative work, subjects were chosen from different places depending on the age groups. The study was conducted on 225 female and male adults between 20 to 50 years, whose tongue were examined, photographed and impression were taken for allowing creation of a database of tongue. Individuals were clinically healthy and had not been exposed to known genotoxic agents and were matched by age and sex. Individuals suffering from HIV and contagious diseases, systemic diseases like hyperthyroidism, gigantism, dwarfism, syphilis, Down syndrome, post-mortem cases etc were excluded from the study.

The examination of tongue was carried out after a prior cleaning with sterile gauze piece, together with rinsing of oral cavity. The subjects were asked to protract the tongue in a relaxed position to prevent marked contraction of striated lingual muscles. The aim of the clinical examination of the tongue was to emphasize the morphological features such as shape and texture. The photographs were taken under the same environmental and lighting condition and from a predetermined distance using a professional Nikon D3300 camera. For capturing tongue images, two views of tongue were taken 


\section{a. Frontal view \\ b. Profile view}

After an informed consent, the detailed analysis for identification purposes was done by taking impression of the dorsal surface (Figure 1) and the lingual lateral edges, with the Neocolloid Impression Material which was directly applied from the level of the oral commissures up to the lingual tip in order to avoid the regurgitation reflex (Figures $2 \& 3$ ). The moulds resulted were filled, in the laboratory, with type III dental stone, so as to have a relevant positive image for identification (Figure 4).
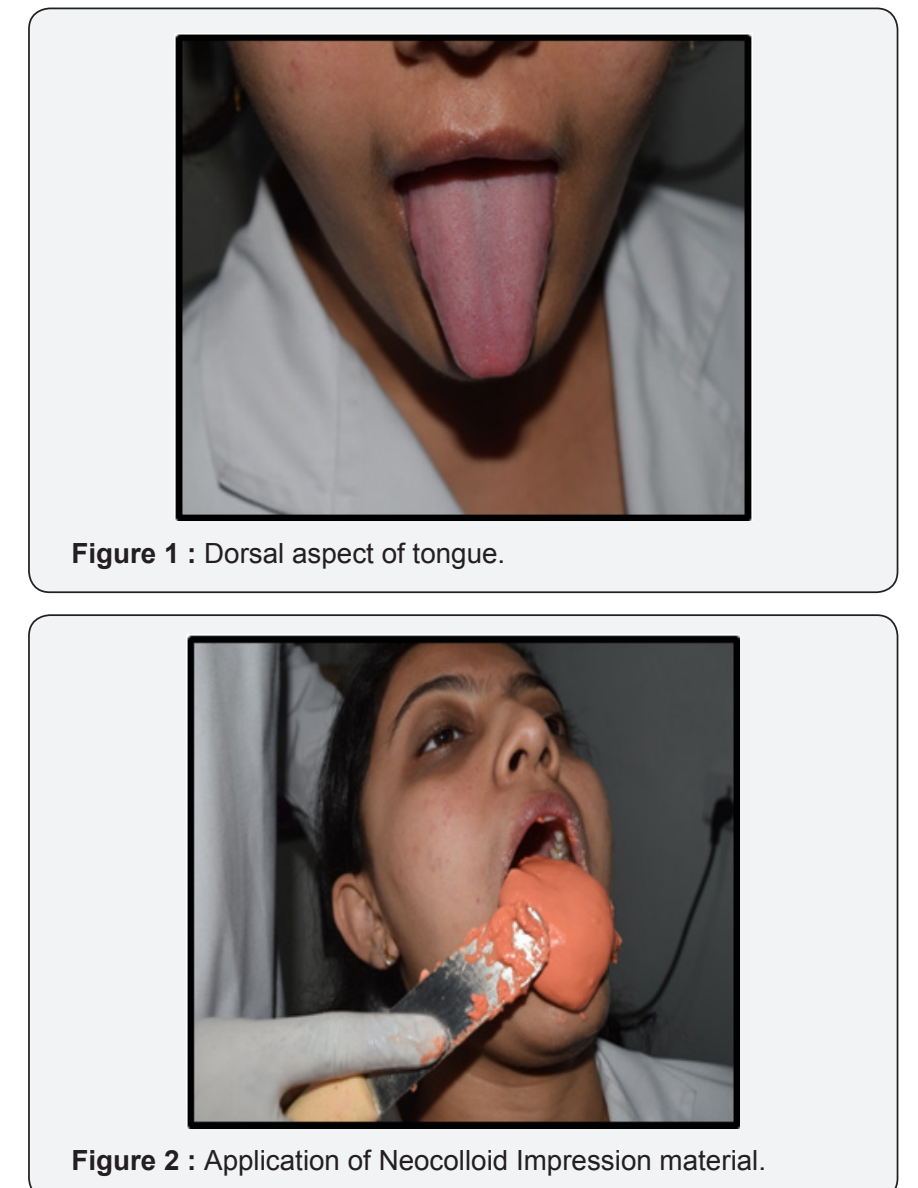

Figure 2 : Application of Neocolloid Impression material.

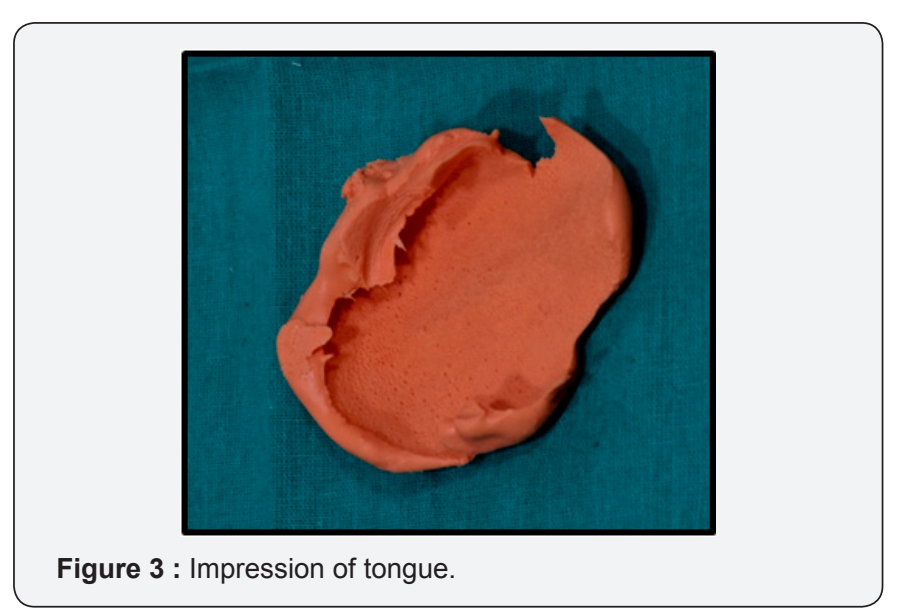

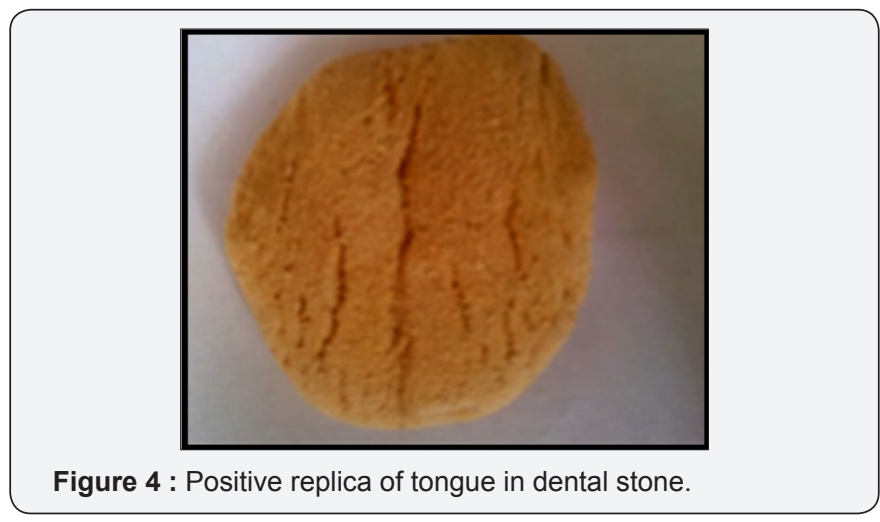

\section{Results and Discussion}

In the current study as far as the tongue shape is concerned, we encountered that 107 individuals $(47.5 \%)$ had square or rectangular shape, 76 individuals (33.77\%) had circular shape, and 42 individuals (18.66\%) had triangular shape [Graph 1]. As far as the texture of the tongue is concerned, it was seen that 43 individuals of 20-30 years of age group, 32 individuals of 30-40 years of age group, 12 individuals of 40-50 years of age group have Normal texture; 13 individuals of 20-30 years of age group, 11 individuals of 30-40 years of age group, 4 individuals of 40-50 years of age group Cleft/ bifid texture; 19 individuals of 20-30 years of age group, 10 individuals of 30-40 years of age group, 23 individuals of 40-50 years of age group have Plaqued texture; 12 individuals of 20-30 years of age group, 19 individuals of 30 40 years of age group, 27 individuals of $40-50$ years of age group have Geographic texture [Graph 2].

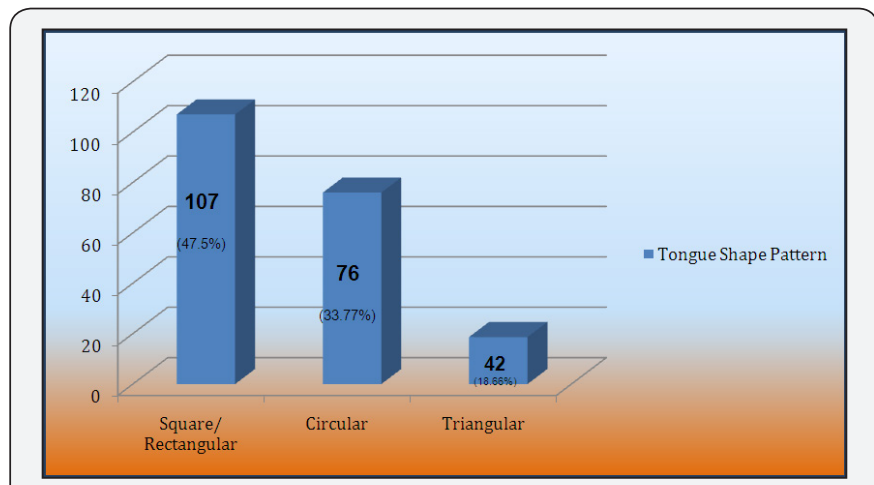

Graph 1 : Distribution based on tongue shape pattern.

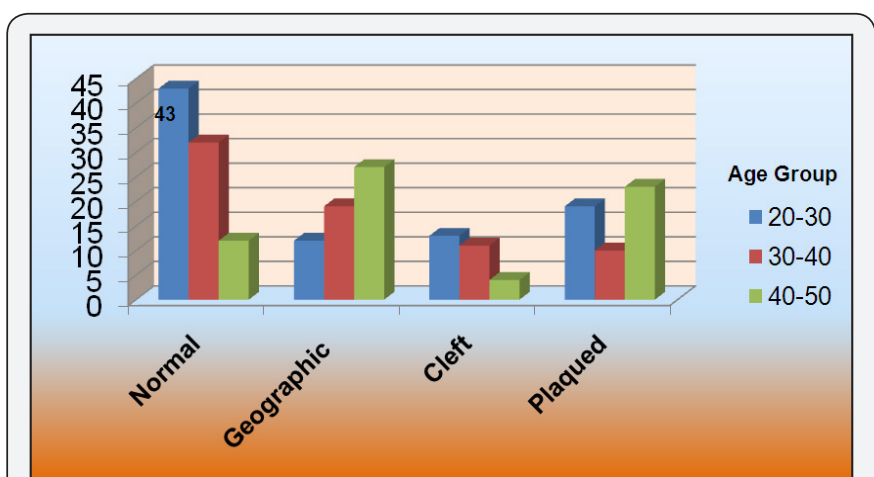

Graph 2 : Distribution based on texture of tongue. 
It was also observed that 38 males (65.5\%) and 20 female (34.5\%) have geographic tongue [Graph 3].

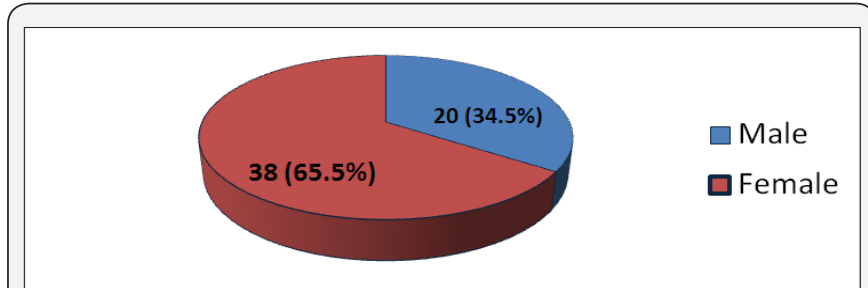

Graph 3 : Distribution of geographic tongue based on gender.

The morphological aspect of the tongue displayed a " $U$ ", with a slightly off rounded tip. It was seen that many fungiform papillae were uniformly arranged specially on the left side than on opposite side which shows a smooth and few papillae, more present within the posterior $1 / 3$ (Figures $5-8$ ). The other general shape was seen as trapezoidal, with a smaller base at anterior aspect and the large base at the level of the oral commissures. Incomplete, shallow medial septum, narrows towards the anterior $1 / 3$, and then tapers down as a flared shape towards the tip of the tongue. Another peculiarity of this tongue is the presence of small and thin, fibrous masses, which form a "compasses" on the right and left side borders of the tongue (Figure 6).

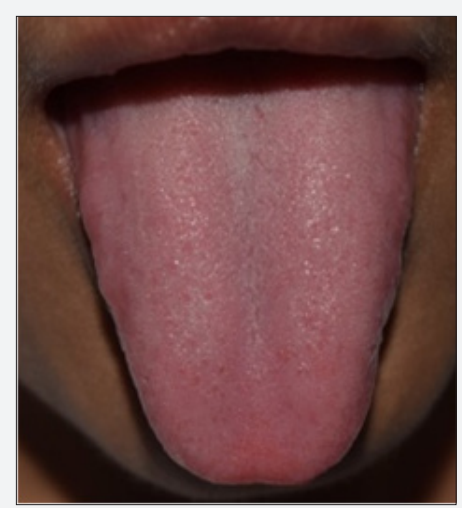

Figure 5 : Frontal image of the tongue of 26 years old male.

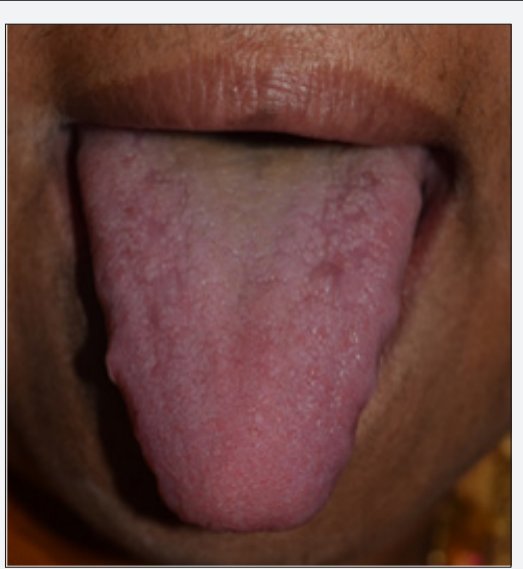

Figure 6 : Frontal image of the tongue of 26 years old female.

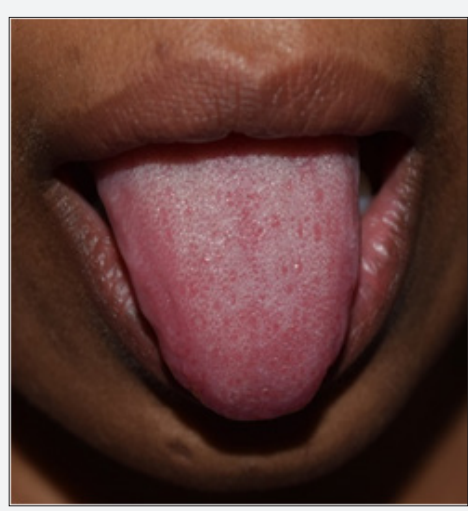

Figure 7 : Frontal image of the tongue of 29 years old female.

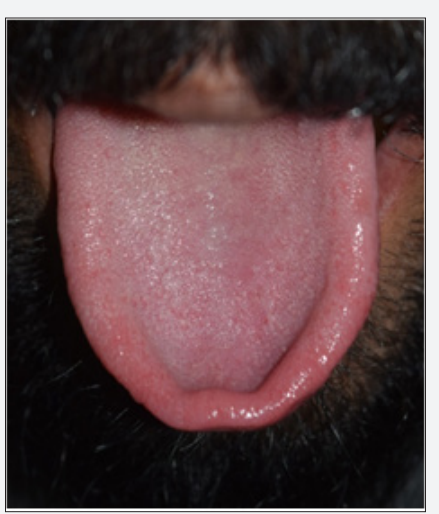

Figure 8 : Frontal image of the tongue of 32 years old male.

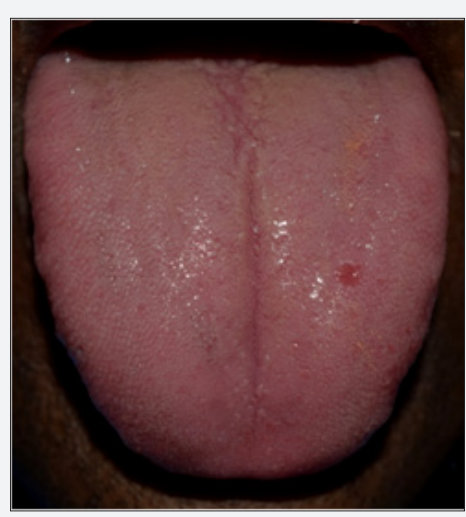

Figure 9 : Frontal image of the tongue of 40 years old male

The tip of the tongue is more of $\mathrm{V}$ shaped extending up to the anterior third of the dorsal surface. The prevalence of foliate and filiform papillae to the detriment of the fungiform ones is small and present particularly on the lingual edges and within the anterior $1 / 3$ of the tongue (Figure 7 ). The examination carried out for the lingual apex showed that the sharp tips are characteristic to female subjects, whereas septate or blunt tips were common for male subjects (Figures 6-11). It was also observed that geographic tongue is characteristic feature seen in female (Figure 11).The grooves present on the dorsal surfaces exemplifies upon the uniqueness of an individual (Figure 9). 
The related lateral grooves have various directions, shapes and sizes, being distributed irregularly over the dorsal surface of the tongue.

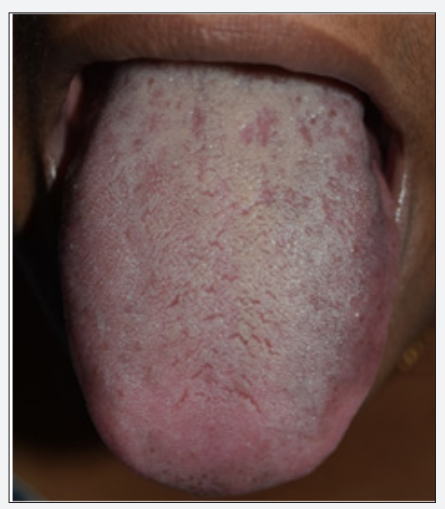

Figure 10 : Frontal image of the tongue of 46 years old female.

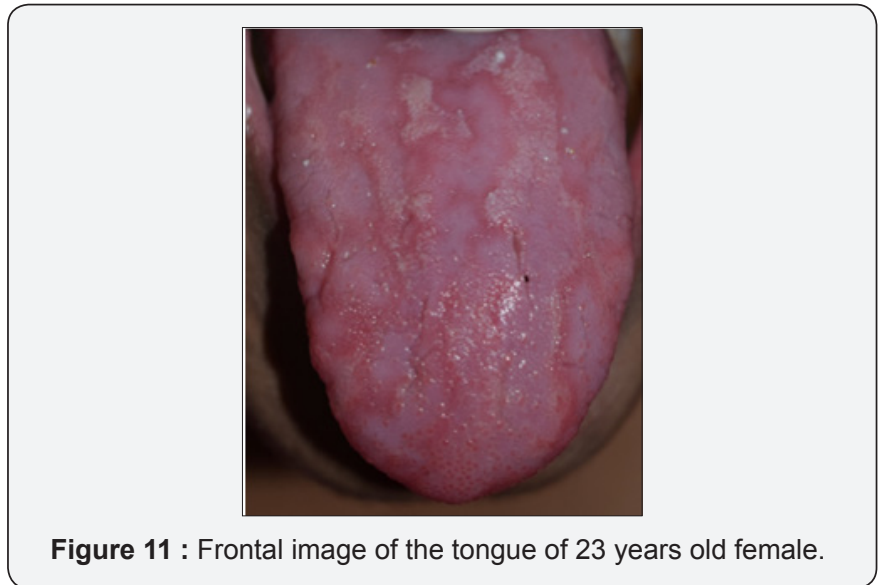

\section{Discussion}

The morphology and the texture provide significant information related to disease and oral hygiene of a person. The uniqueness of the tongue is showcased by the analysis of shape and texture reveals visible differences between one individual and another, thereby making it a useful tool in personal identification [4]. It not only can be a tool for identification but can convey a lot of information regarding health status of an individual according to TCM [5]. The characteristic features observed on the dorsal surface of the tongue have been classified as:

\section{According to shape:}

a) Square or rectangular

b) Triangular

c) Circular

6.2. According to texture:

a) Normal

b) Fissural c) Cleft/ bifid

d) Plaqued

e) Geographic

The geographic tongue is characteristic feature seen in female subjects than in male according to Stefansu et al that correlated with our study [1].

In our study, it was seen that the plaqued tongue was very common in elder people and especially in males. According to Stefansu et al, scrotal tongue were common than geographic tongue and the scales are tipped by female subject. In our study, geographic tongue was more commonly seen that scrotal tongue [1]. In our study, we evaluated the shape and the texture of the dorsal aspect of the tongue. To our best knowledge, there was no such study conducted on tongue and to assess its role in personal identification.

\section{Conclusion}

Forensic odontology is a field of dentistry which analyses dental evidence in the interest of justice. The data obtained from the oral cavity can help in identifying individual or providing information needed in a legal process. The human tongue promises to deliver a level of uniqueness in shape, texture and is suitable for the use in identity recognition. It can be easily examined thus, making it real proof of life with genetic independence, in the sense that no two individuals have similar tongue prints. The morphological aspect of the tongue is unique for each and every individual. The dorsal surface of the tongue provides significant details from a morphological and structural point of view due to:

a. Genetic independence - no two tongues are same in its shape and surface textures.

b. Stability over time.

c. Physical protection that it is well protected in mouth so that extremely difficult to forge (the main advantage).

The lingual impression, together with its photographic image, may constitute secure methods for forensic dentistry identification, in addition to rugoscopy and cheiloscopy. Only little investigation has been conducted on analyzing tongue as a biometrics. Therefore, a continuation of this work will investigate the fusion of all possible tongue features including colour, shape and texture in order to better in human identification.

\section{References}

1. Stefanescu CL, Popa MF, Candea LS (2014) Preliminary study on the tongue-based forensic identification. Rom J Leg Med 22: 263-266.

2. Zhi Liu, Jing-Qi Yan, David Zhang, Qun-Lin Tang (2007) A tongue-print image database for recognition. Proceedings of the Sixth International Conference on Machine Learning and Cybernetics: Hong Kong, 19-22. v. 4, p. 2235-2238.

3. Radhika T, Jeddy N, Nithya S (2016) Tongue prints: A novel biometric and potential forensic tool. J Forensic Dent Sci 8: 117-119. 
4. Anastasi JK, Currie LM, Kim GH (2009) Understanding diagnostic reasoning in TCM practice: Tongue diagnosis. Altern Ther Health Med 15: 18-28.

5. Wangmeng Zuo, Kuanquan Wang, Zhang D, Hongshi Zhang (2004) Combination of polar edge detection and active contour model for automated tongue segmentation. Proceedings of Third International Conference of Image and Graphics pp. $270-273$.

This work is licensed under Creative Commons Attribution 4.0 License

DOI : 10.19080/JFSCI.2018.07.555723
6. Rohaila naaz (2011) Tongue biometric and its application in public use system. 3rd international conference on machine learning and computing.

7. Diwakar M, Maharshi M (2013) An extraction and recognition of tongue-print images for biometrics authentication system. Int J Comput Appl 61: 36-42.

\section{Your next submission with Juniper Publishers} will reach you the below assets

- Quality Editorial service

- Swift Peer Review

- Reprints availability

- E-prints Service

- Manuscript Podcast for convenient understanding

- Global attainment for your research

- Manuscript accessibility in different formats (Pdf, E-pub, Full Text, Audio)

- Unceasing customer service

Track the below URL for one-step submission https://juniperpublishers.com/online-submission.php 